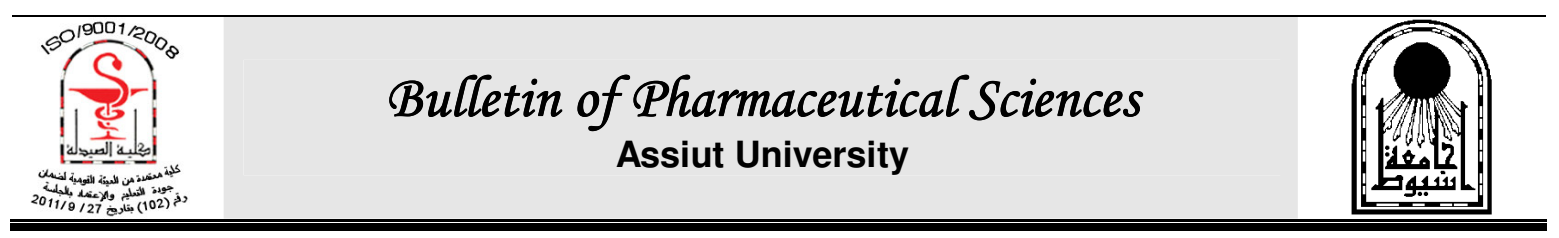

\title{
ASSESSMENT OF SELF MEDICATION PATTERN OF PHARMACIST IN ASEER REGION, SAUDI ARABIA
}

\author{
Khaled Mohammed Alakhali \\ Department of Clinical Pharmacy, College of Pharmacy, King Khalid University, Abha, \\ Kingdom of Saudi Arabia
}

\begin{abstract}
Background: Self-care and self-medication raise the issue of the responsibility of consumers and patients to ensure that the care or medication they select is appropriate to their needs, safe and effective. Equally, they pose several questions for pharmacists.

Objective: The purpose of this study was to evaluate and characterize the perceptions of pharmacists about self medication pattern of drugs in the patients.

Method: It was a cross sectional study which involved the pharmacist $(n=87)$ working in community pharmacies and the hospital pharmacies who self medicate the patients. A structured questionnaire was prepared which consisted of the basic details of the pharmacists and questions regarding the attitude of the pharmacists regarding the self medication for evaluation.

Results: The majority of the pharmacists were Egyptian (68.96\%), with a Bachelor degree (86.2\%). Pharmacist indicated that self medication was found to be common among adult $(67.81 \%)$ males $(73.56 \%)$. Economical reasons $(67.8 \%)$ and time saving (58.6\%) were cited as an important reason for self-medication. Headache, cough, fever and cold were major conditions for which self-medication was sought by patients and pharmacist justified dispensing of drug for self-medication by patients as the conditions being simple and unwarranted intervention of physicians.

Conclusion: There is a need for self-medication in self-care; hence the role of the pharmacist must be extended. To address this issue, the pharmaceutical societies regulatory agencies should discuss communication, evaluation, quality, screening, training and supervision, collaboration and performance review of the pharmacist to make them more competent for independent prescribing in self-medication in self care by patients.
\end{abstract}

\section{INTRODUCTION}

All over the world, millions of people visit pharmacies for their daily health care needs. Pharmacists are placed at the first point of contact in the healthcare system due to their easy accessibility ${ }^{1}$. Non-medical prescribers are a large and growing workforce. Improving patient access to medicines and making best use of the clinical skills of non-medical health professionals, particularly pharmacists and nurses, are among the aims of recent changes in prescribing legislation in Great Britain ${ }^{2}$. In many developing countries, pharmacists and pharmacy attendants play an important role in fostering self-medication among the public ${ }^{3}$.
Pharmacies (chemist shops and drug stores) are not only sites where medicines are bought and sold, they are also places where information and advice on common health problems and treatment is sought routinely ${ }^{4}$ this may be due to the change in role of the pharmacist over the past two decades. Pharmaceutical care is growing in importance with the challenges of self-care. For pharmacists, their greater involvement in self-care means greater responsibility towards their customers and an increased need for accountability ${ }^{5}$. However a major short of self-medication is the lack of clinical evaluation of the condition by a trained medical professional, which could result in missed diagnosis and delays in appropriate

Received in 19/6/2016 \& Accepted in 27/10/2016 
treatments $^{6}$. On the other hand independent prescribing for pharmacists is a more recent development and permits the management of diagnosed and undiagnosed conditions, prescribing any licensed medicine (other than controlled drugs) within the pharmacist's competence, with no need for formal medical collaboration ${ }^{7}$. Laws regulating the profession of pharmacy in Saudi Arabia demands professionalization of pharmacy operations and prohibit the practice of pharmacy by persons other than licensed pharmacists. In addition, a pharmacist is required to dispense drugs on prescription only, except those drugs defined as OTC $^{8}$. However, a study conducted in the eastern province of Saudi Arabia by Al-Freihi et al. ${ }^{9}$ draws attention to the potential for drug misuse due to the lack of adherence to this regulation governing the dispensing of drugs by community pharmacies. Taking into consideration the policies, initiatives, that have been developed to improve safety of prescribing by pharmacist in countries such as Great Britain and the lack of adherence in prevailing regulation in Saudi Arabia and transforming role of pharmacist to improve patients access, adherence, and selfmanagement of medication, it was thought worthwhile to evaluate the perceptions of pharmacists in response to self-care and selfmedication needs.

\section{MATERIALS AND METHODS}

\section{Study design}

It was a Cross sectional study which involved the pharmacist $(n=87)$ working in community pharmacies and the hospital private pharmacies who self medicate the patients. A structured questionnaire was prepared and which consisted of the basic details of the pharmacists and questions regarding the attitude of the pharmacists toward the self medication. Pharmacies from various parts of the Aseer Region and pharmacists of different nationalities were selected and the questionnaire was given to the participants and the participants were asked to fill the questionnaire. This study was carried out between February - May, 2014. Data was analyzed using Microsoft Excel. Data were expressed as mean (standard deviation) for continuous variables and as frequency for categorical variables.

\section{RESULTS AND DISCUSSION}

\section{Results}

\section{Characteristics of the study population}

A total of 87 pharmacists who met the selection criteria completed the survey. Sociodemographic data of the respondents were shown in table 1 . The majority of the pharmacists were Egyptian (68.96\%), others were Yemani (9.19\%), Jordanian (8.04\%), Saudi $(4.59 \%)$, Syrian (3.44\%), Indian (2.29\%), Sudani (2.29\%), and Bangladeshi $(1.14 \%)$ and $86.2 \%$ were holding a Bachelor degree, $(10.34 \%)$ were Master and (3.4\%) were holding PharmD degree.

Table 1: Demographic Characteristics $(n=87)$.

\begin{tabular}{|c|c|c|c|}
\hline \multicolumn{2}{|c|}{ Characteristics } & Number & $\%$ \\
\hline \multirow{3}{*}{$\begin{array}{l}\text { Type of } \\
\text { Pharmacy }\end{array}$} & $\begin{array}{l}\text { Chain } \\
\text { Pharmacies }\end{array}$ & 49 & 56.32 \\
\hline & $\begin{array}{l}\text { Single } \\
\text { Pharmacy }\end{array}$ & 22 & 25.28 \\
\hline & $\begin{array}{l}\text { Hospital } \\
\text { Pharmacy }\end{array}$ & 16 & 16.49 \\
\hline \multirow{8}{*}{$\begin{array}{c}\text { Nationality } \\
\text { of } \\
\text { Pharmacist }\end{array}$} & Egyptian & 60 & 68.96 \\
\hline & Yemani & 8 & 9.19 \\
\hline & Jordanian & 7 & 8.04 \\
\hline & Saudi & 4 & 4.59 \\
\hline & Syrian & 3 & 3.44 \\
\hline & Indian & 2 & 2.29 \\
\hline & Sudani & 2 & 2.29 \\
\hline & Bangladeshi & 1 & 1.14 \\
\hline \multirow{3}{*}{$\begin{array}{c}\text { Educational } \\
\text { Level }\end{array}$} & Bachelor & 75 & 86.20 \\
\hline & Master & 9 & 10.34 \\
\hline & PharmD & 3 & 3.44 \\
\hline \multirow{4}{*}{$\begin{array}{l}\text { Professional } \\
\text { Experience }\end{array}$} & $0-5$ years & 15 & 17.24 \\
\hline & $5-10$ years & 32 & 36.78 \\
\hline & 10-15 years & 33 & 37.93 \\
\hline & $\begin{array}{l}\text { Above } 15 \\
\text { years }\end{array}$ & 7 & 8.04 \\
\hline
\end{tabular}

Characteristics of patients who adopt self medication practice as indicated by pharmacists

Self medication was found to be common among males $(73.56 \%)$ and females $(26.43 \%)$. The majority of them were adult $(67.81 \%)$, elderly $(18.39 \%)$ and children $(13.79 \%)$ (Table 2) 
Table 2: Characteristics of patients who adopt self medication practice.

\begin{tabular}{|c|c|c|}
\hline Characteristics & Status & $\begin{array}{c}\text { Number= } \\
87(\%)\end{array}$ \\
\hline \multirow{2}{*}{ Gender } & Male & $64(73.56)$ \\
\cline { 2 - 3 } & Female & $23(26.43)$ \\
\hline \multirow{3}{*}{ Age (years) } & Adult & $59(67.81)$ \\
\cline { 2 - 3 } & Elderly & $16(18.39)$ \\
\cline { 2 - 3 } & Children's & $12(13.79)$ \\
\hline
\end{tabular}

\section{Responses on reasons for self-medication}

Reasons are shown in table 3 these include illness is minor, seeking quick relief, time saving, economic cost, privacy, no hospital nearby and the condition does worth seeing physicians.

Table 3: Reasons for self medication.

\begin{tabular}{||l|c|c||}
\hline \multicolumn{1}{|c|}{ Reasons } & Number & $\%$ \\
\hline Economic Cost & 59 & 67.8 \\
\hline Time Saving & 51 & 58.6 \\
\hline Mild illness & 42 & 48.3 \\
\hline Privacy & 10 & 11.5 \\
\hline Quick relief & 23 & 26.4 \\
\hline No hospital nearby & 25 & 28.7 \\
\hline $\begin{array}{l}\text { Conditions does not worth } \\
\text { seeing physician }\end{array}$ & 22 & 25.3 \\
\hline
\end{tabular}

Pharmacist preferred to give drugs for patients described symptoms associated with pain (head, gastric, body), cough, fever, allergy and other indications described in table 4.
Categories of the agents commonly dispensed for self-medication are indicated in the figure 1. Most of patients ask for self medication by mentioning the symptoms (63.2\%), others by mentioning the color/shape/dosage form/price of the medicines (58.6\%), and the least by generic name of the drug (10.3\%) as shown in figure 2. Figure 3 give the justification of pharmacist for self medication.

Table 4: Pharmacist preferences drug indications for self-medication.

\begin{tabular}{||l|c|c||}
\hline \multicolumn{1}{|c|}{ Symptoms } & Number & $\%$ \\
\hline Head Ache & 69 & 79.31 \\
\hline Cough & 67 & 77.01 \\
\hline Fever & 41 & 47.13 \\
\hline Influenza & 43 & 49.43 \\
\hline Gastric Pain & 32 & 36.78 \\
\hline Allergy & 28 & 32.18 \\
\hline Diarrhea & 41 & 47.13 \\
\hline Constipation & 41 & 47.13 \\
\hline Body Pain & 41 & 47.13 \\
\hline Peptic ulcer disease & 17 & 19.54 \\
\hline $\begin{array}{l}\text { Gastro esophageal } \\
\text { reflux disease }\end{array}$ & 10 & 11.49 \\
\hline $\begin{array}{l}\text { Fungal/Microbial } \\
\text { infections }\end{array}$ & 8 & 9.20 \\
\hline $\begin{array}{l}\text { Sex Related } \\
\text { Problems }\end{array}$ & 12 & 13.79 \\
\hline Contraception & 5 & 5.75 \\
\hline Insomnia & 6 & 6.90 \\
\hline
\end{tabular}

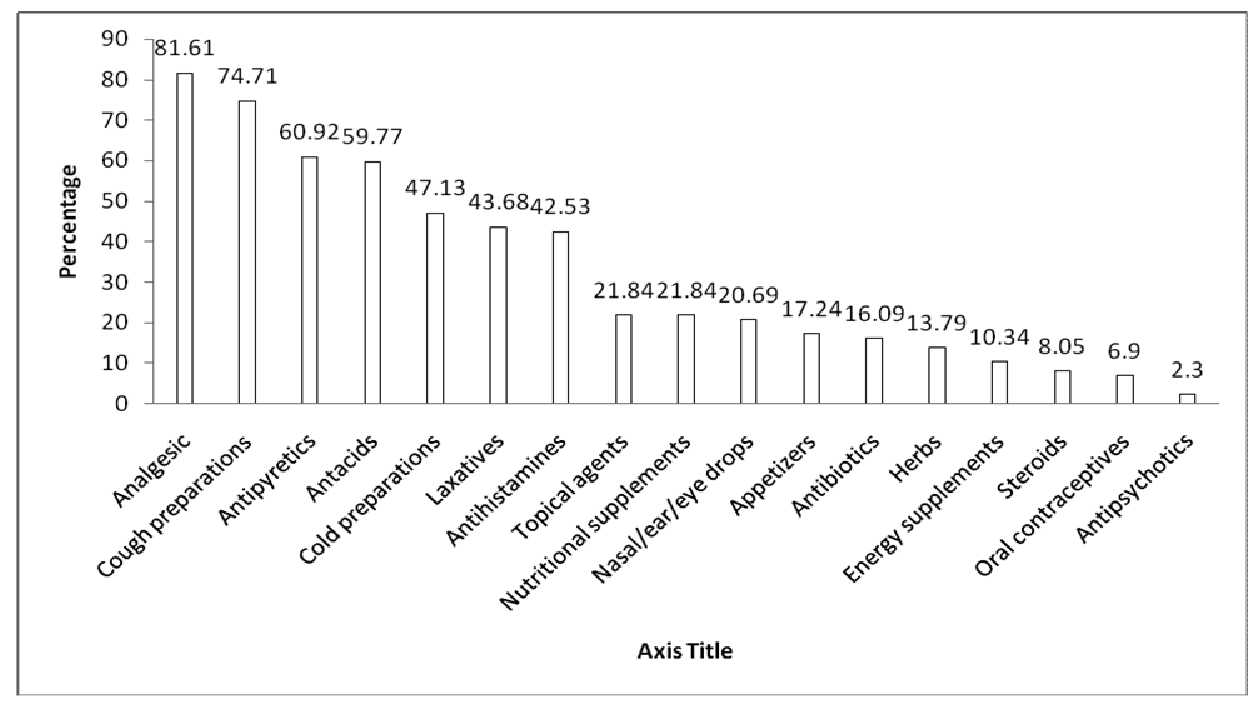

Fig. 1: Categories of the agents commonly dispensed for self-medication. 


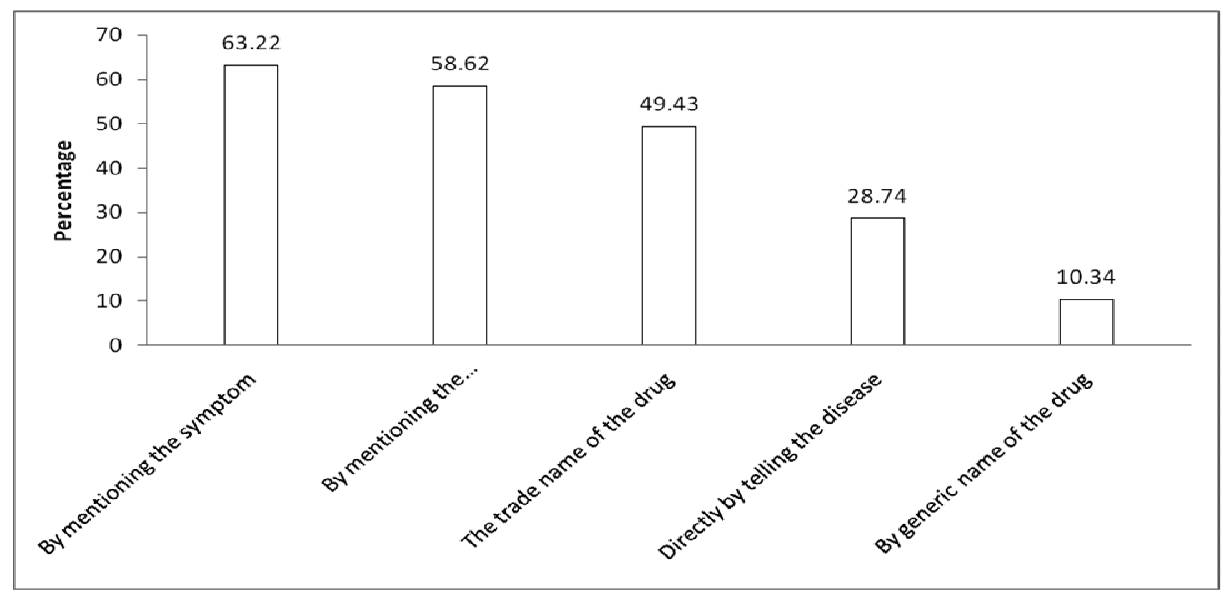

Fig. 2: Ways by which the patients ask for self-medication.

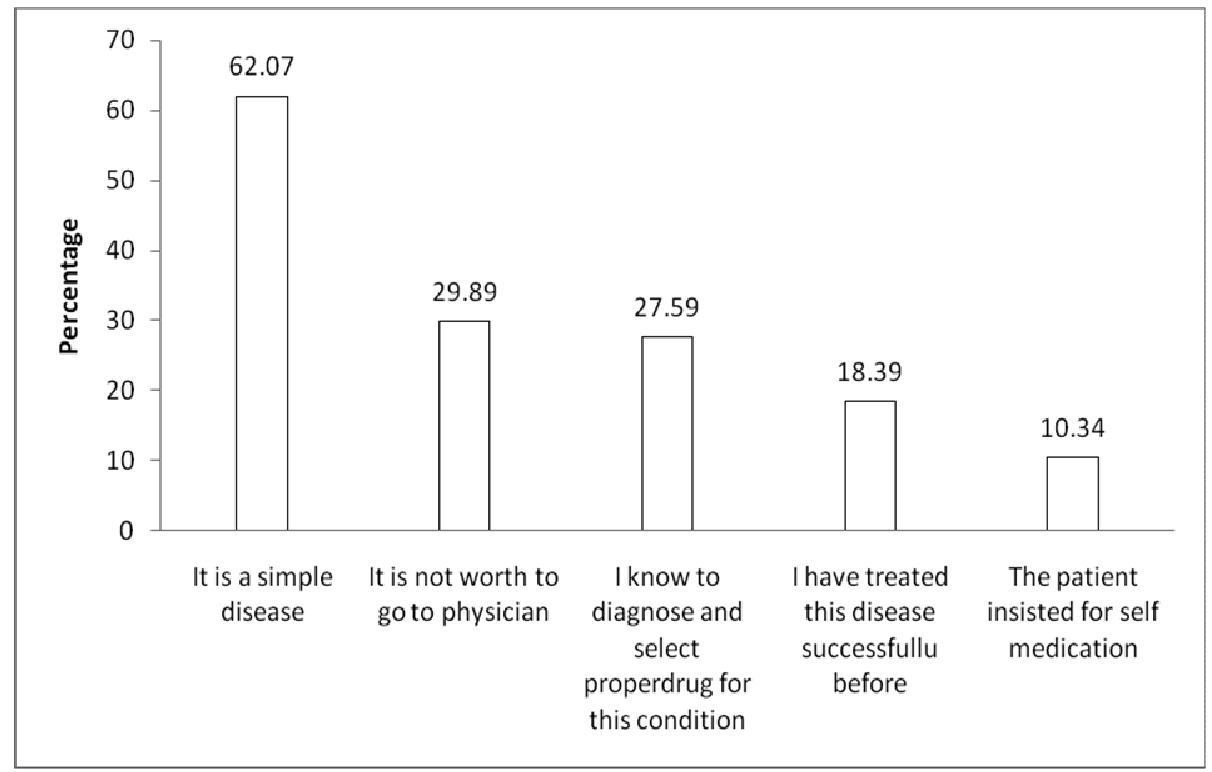

Fig. 3: Pharmacist justification for self-medication.

\section{Discussion}

Majority of the respondents had the Bachelor of Pharmacy degree with 10 to 15 years post qualification experience. There were only male respondents in spite of conducting the study among different practice setting. The current results are in agreement with previous study $^{10}$ however our results differ when compared to a study ${ }^{11}$ which found a higher prevalence of female pharmacists, which was in accordance with theories of feminization of the profession in Brazil. Males were found to self medicate more $(73.56 \%)$ than females $(26.43 \%)$.

Practices of self medication were found more in age group of adults $(67.81 \%)$. These results are in agreement with the previous study $^{12}$ however some studies demonstrate no association between age and self medication ${ }^{13}$.

In current study demonstrate self medication was found to be common among males and females, however another study demonstrate that females self medicated more than males ${ }^{14}$ this may be due to the fact that 
restricted movement outside the house and a se condary status in the household, however a study by Saeed $(1988)^{15}$ revealed no association between gender and self medication. Though the common reason for self-medication demonstrate is economical reason despite the fact that most of the population in Saudi Arabia are eligible for free public health services apart from time saving and mild illness (symptoms) in some cases, the main reasons could be triviality of the symptoms, to save money and time, lack of gravity to go and see a physician because they can take care of themselves or previous medical prescription for related symptoms are associated with self medication ${ }^{16}$. In the present investigation pharmacist cited varieties of conditions such as head ache, cough, fever, influenza, gastric pain, allergy, diarrhea, constipation and body pain other conditions demonstrate in table 4 as common ailments for which the patients seek self-medications, and these results are inline with the previous studies $^{17 \& 18}$. Several medications reportedly used for this practice include analgesics, cough preparations, antipyretics, as major drug category and the least was oral contraceptive and antipsychotics as shown in figure 1. Trade name, color, shapes and by indicating the symptoms to the pharmacist were common means of identification and less frequently by generic names by the patients. The ability of the patient to recognize the drugs by their trade name or generic name may be attributed to the fact that most of the patient who self medicated may be educated and these results are in agreement with the previous study ${ }^{19}$, however those with low education recognized the drugs with color and shape of the drug. The majority of the pharmacists had a positive attitude towards self-medication, saying that it was acceptable and that those condition for which the patients approach for medications are simple diseases which does not worth consulting a physician and that he as a pharmacist has treated such conditions earlier successfully and that he has adequate knowledge to do so. A study on patient selfcare and roles of pharmacists indicated the importance of patients to self-care of their chronic conditions and they also supported pharmacists to be involved in patient self-care and take a major role in managing patients' medication issues ${ }^{20}$. However pharmacy professionals also need directions concerning how they can best fulfill their responsibilities, not only at community level, but also through the development and distribution of drugs. In addition, ethical, regulatory and quality assurance aspects should be addressed, as well as consumers' attitude and perceptions. To ensure up-to-date quality service, the pharmacist must be encouraged to participate in continuing professional development activities such as continuing education.

\section{Conclusion}

The pharmacist can play a key role in helping people to make informed choices about self-care, and in providing and interpreting the information available. However for community pharmacist who do not contact with medical team on regular basis there is a need to demonstrate their professional competence such that their consultation skills are evaluated. This can be possible only when mechanisms are developed by policy makers and regulatory agencies to explore and evaluate the pharmacist prescribing in the self medication and self care by the patients.

\section{REFERENCES}

1- S. Hanafi, et al., "Evaluation of community pharmacists' knowledge, attitude and practice towards good pharmacy practice in Iran", J. Pharm. Care, 1 (1), 19-24 (2013)

2- D. C. Stewart, J. George, D. E. Pfleger, C. M. Bond, H. L. Diack, I. T. Scott Cunningham and D. J. McCaig, "Pharmacist supplementary prescribing training: A study of pharmacists' perceptions and planned participation", International Journal of Pharmacy Practice, 15, 319-25 (2007).

3- P. K. Kulkarni, M. Khan and A. Chandrasekhar, "Self medication practices among urban slum dwellers in South Indian City", Int. J. Pharm. Bio. Sci., 3 (3), 81-7 (2012).

4- F. Rabbani, et al., "Behind the counter: Pharmacies and dispensing patterns of pharmacy attendants in Karachi", J. Pak. Med. Assoc., 51 (4), 149-53 (2001). 
5- Report of the $4^{\text {th }}$ WHO Consultative Group on the Role of the Pharmacist in Self Care and self-medication. The Hague, The Netherlands, August (1998).

6- C. O. Omolase, O. E. Adeleke, A. O. Afolabi and O. T. Afolabi, "Self medication amongst general outpatients in a Nigerian community hospital", Ann. Ib. Postgrad. Med., 5 (2), 64-7 (2007).

7- D. C. Stewart, et al., "Views of pharmacist prescribers, doctors and patients on pharmacist prescribing implementation", International Journal of Pharmacy Practice, 17, 89-94 (2009).

8- S. A. Bawazir, "Prescribing pattern at community pharmacies in Saudi Arabia", International Pharmacy Journal, 6, 22224 (1992).

9- H. Al-Freihi, S. G. Ballal, A. Jaccarini, M. S. Young, Z. Abdul-Cader and M. El Mouzan, "Potential for drug misuse in the eastern province of Saudi Arabia", Anal. Saudi Med., 7, 301-5 (1987).

10- T. O. Fakeye, R. Adisa and S. J. S. Showande, "Attitude and opinion of Nigerian community pharmacists to self medication practices", Afr. J. Pharm. Pharmacol., 6 (15), 1147-52 (2012).

11- Rocha, et al., "What do Brazilian community pharmacists know about selfmedication for minor illnesses? A pilot study in the northeast of Brazil", J. App. Pharm. Sci., 4 (5), 012-020 (2014).

12- S. A. Alghanim, "Self-medication practice among patients in a public health care system", EMHJ, 17 (5), 409-16 (2011).
13- U. Rodriguez-Benito, R. Magro-Peteguer, M. Masip-Lopez, R. Vacas Gamido and B. Urbano-Rodriguez, "Self medication in general paediatrics", Atn. Primaria., 13 (6), 313-16 (1994).

14- P. Angeles-Chimal, M. L. Medina-Flores and J. F. Molina-Rodríguez, "Selfmedication in a urban population of Cuernavaca, Morelos", Salud. Publica. Mex., 34 (5), 554-61 (1992).

15- A. Saeed, "Self medication among primary care patients in Faradak clinic in Riyadh", Soc. Sci. Med., 27 (3), 287-9 (1988).

16- A. O. Afolabi, "Factors influencing the pattern of self-medication in an adult Nigerian population", Annals of African Medicine, 7 (3), 120-7 (2008).

17- E. Balamurugan and K. Ganesh, "Prevalence and pattern of self-medication use in coastal regions of South India", BJMP, 4 (3), a428 (2011).

18- A. Sandeep, et al., "Self-medication: Knowledge and practice among urban and rural population", International Journal of Pharmaceutical \& Biological Archives, 4 (3), 488-92 (2013).

19- P. Patel, D. Solanki and N. Patel, "A Qualitative study on self-medication practices in urban settings of Jamnagar, Gujarat", Int. J. Res. Med., 2 (3), 38-41 (2013).

20- J. H. You, F. Y. Wong, F. W. Chan, E. L. Wong and E. K. Yeoh, "Public perception on the role of community pharmacists in self-medication and self-care in Hong Kong", BMC Clin. Pharmacol., 11, 19, doi: 10.1186/1472-6904-11-19 (2011). 


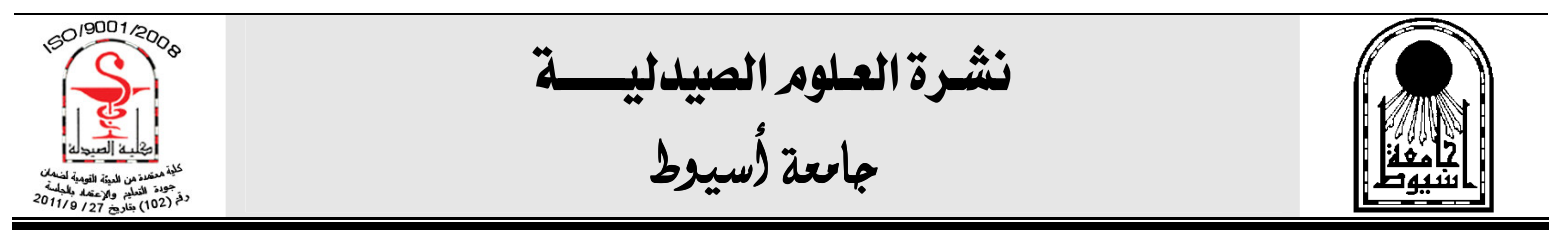

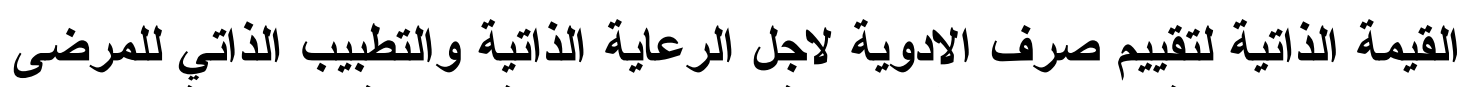

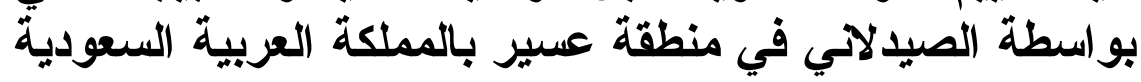 \\ خالد محمد الاكحلي}

\section{قسم الصيدلة السريرية ، كلية الصيدلة ، جامعة الملك خالد ، أبها ، المملكة العربية السعودية}

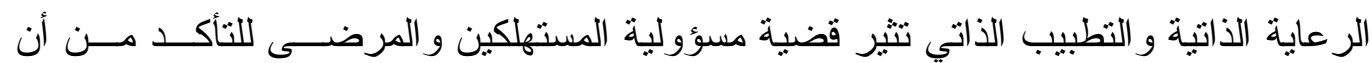

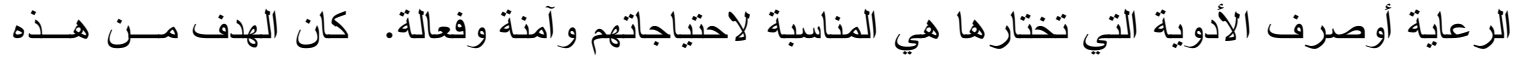

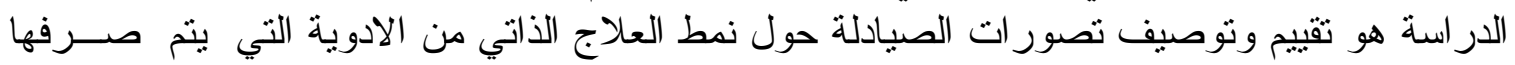

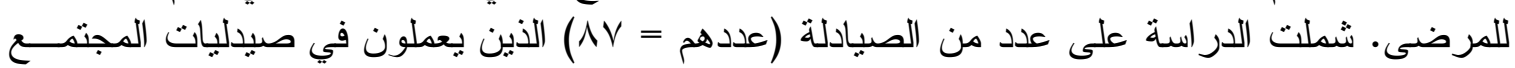

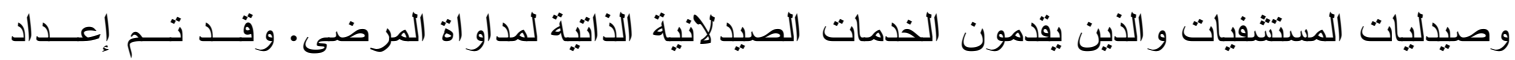

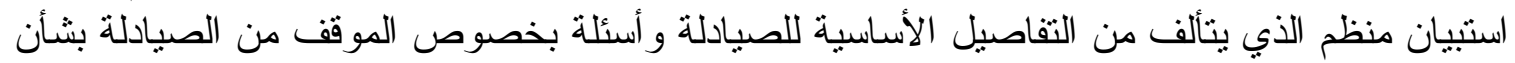

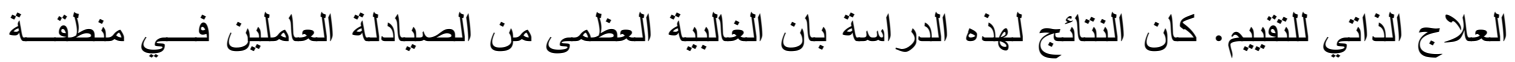

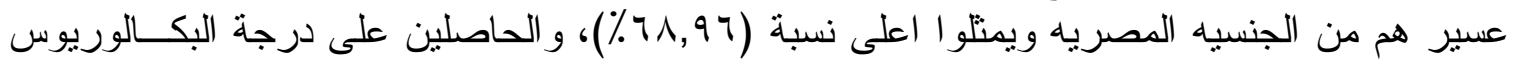

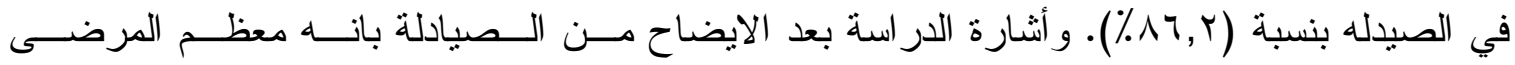

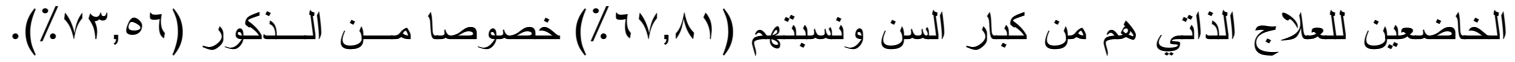

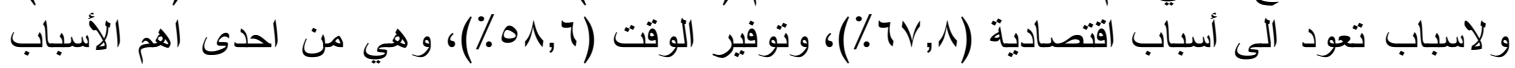

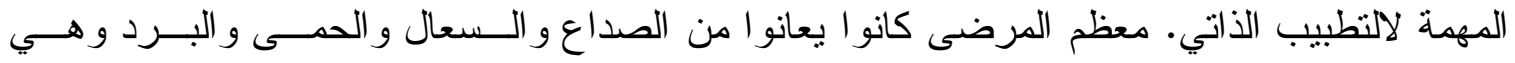

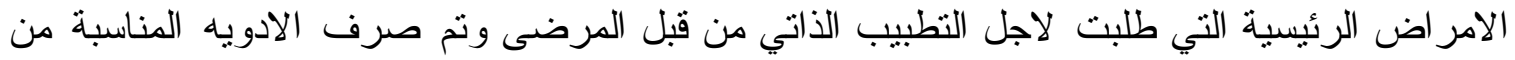

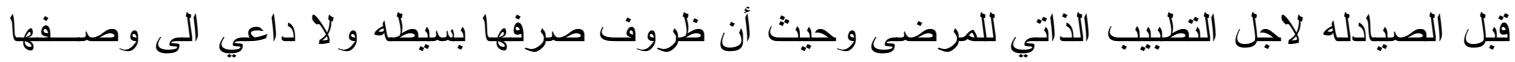

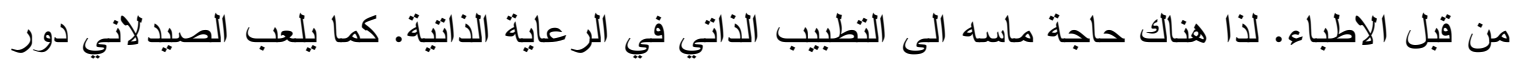

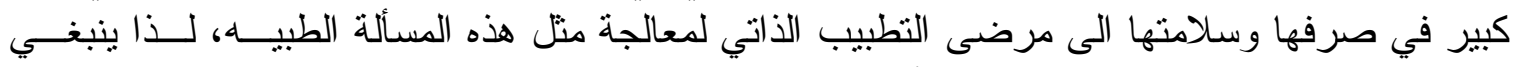

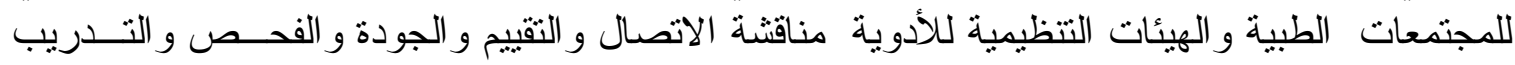

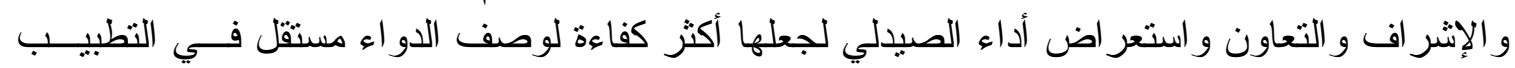
الذاتي في الرعاية الذاتية من قبل المرضى. لأنع. 